\title{
The Application and Influence of Artificial Intelligence in the Financial Sector and its Countermeasures
}

\author{
Xin Yang * \\ Business School \\ Nanfang College of Sun Yat-sen University \\ Guangzhou, China
}

\author{
Xiajun Yi \\ Department of Finance and Economics \\ Guangzhou Vocational and Technical University of Science \\ and Technology \\ Guangzhou, China
}

\author{
Chunting $\mathrm{Wu}$ \\ Business School \\ Nanfang College of Sun Yat-sen University \\ Guangzhou, China
}

\begin{abstract}
This paper aimed to describe the concept and characteristics of artificial intelligence, as well as the development of artificial intelligence in the financial sector. The paper also analyzed the application of artificial intelligence in the financial industry, and explained how the development of artificial intelligence affected the financial sector and the economy. In the end, the research put forward the countermeasures of the financial industry in the face of the advancement of artificial intelligence.
\end{abstract}

Keywords-Artificial Intelligence; Financial Sector; Countermeasure

\section{INTRODUCTION}

With the development of science and technology, the research of artificial intelligence has also made a major breakthrough. In recent years, the application of artificial intelligence has always been a hot topic. The emergence of artificial intelligence and its subsequent development had brought huge changes and convenience which human beings will gradually accept and enjoy. The application of artificial intelligence is also wider, such as medicine, product manufacturing, financial trade and other aspects. The financial industry seizes this opportunity and takes the lead in embracing intelligence, moving from traditional financial services to intelligent financial services. The application of artificial intelligence in the financial sector is not only an opportunity but also a challenge. It brings convenience, also brings a huge impact. Artificial intelligence technology solved some traditional technical problems, but a large number of posts have been replaced. There are some potential risks, so the financial sector needs to make adjustments and countermeasures to face the development and impact of financial service intelligence.

The application of artificial intelligence in the financial sector is mainly realized through technologies such as machine learning, knowledge map, natural language

This work was supported by The Innovative Young Talents Program of Guangdong Province, China (Grant No. 2018WQNCX285) processing, and computer vision. The financial industry is the first to embrace intelligence. The integration of artificial intelligence with the financial industry actively transformed financial services to intelligent services. The artificial intelligence stage of the financial industry is based on the development of IT + finance and Internet + finance, from magnetic stripe of IT + finance model, IC technology, ATM machine, POS machine to mobile banking of Internet + finance mode, online banking, and card-free payment. Now the development of artificial intelligence has expanded to customer service, face recognition technology, intelligent network, and intelligent risk analysis. For example, when a customer wants to purchase a wealth management product, he can use this artificial intelligence analysis system to understand his investment habits, risk tolerance, and choose his investment strategy. According to the report of iResearch, the scale of IT investment in China's banking industry is expected to increase year by year from 2012 to 2020, and it has exceeded 100 billion yuan in 2017[1]. The scale is very large. In the future, the financial industry is likely to take the lead in achieving comprehensive and intelligent services[1].

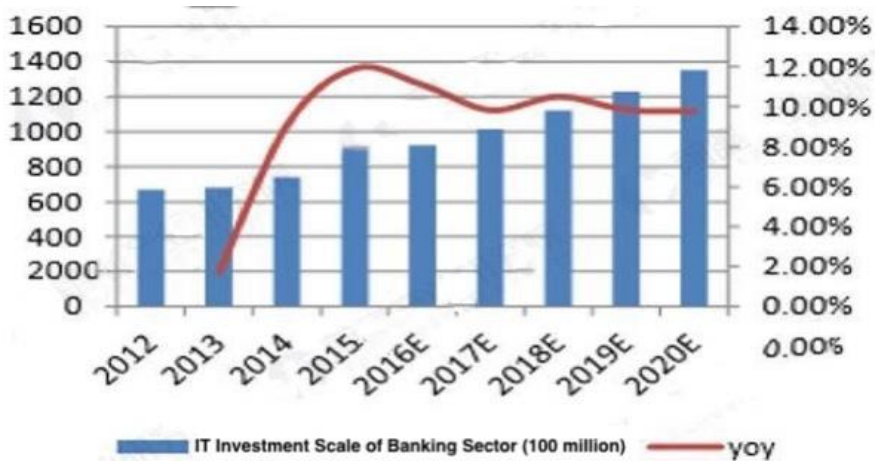

Fig. 1. China Banking IT Investment Scale and Growth Rate (2012-2020) 


\section{APPLICATION OF ARTIFICIAL INTELLIGENCE IN THE FINANCIAL INDUSTRY}

\section{A. Intelligent customer service}

Intelligent customer service is the most common application of artificial intelligence technology in financial sector. Financial institutions use voice recognition and natural language processing technology to create intelligent customer service robots and provide online intelligent customer service. Through the dialogue between intelligent customer service and customers, financial institutions can understand the basic situation of customers, make targeted questions to customers, and collect and extract important information to analyze and grasp customer needs, and provide intelligent services to customers. In the question and answer exchange, the problem is raised in a targeted manner to understand and analyze the customer's needs. For example, if you want to handle the inquiry business, you can directly speak the inquiry service or operate according to the instructions of the intelligent system.

At present, many banks have introduced intelligent service systems, such as the Bank of China. Customers only need to bring their ID cards to the Bank of China's outlets to handle card business through the intelligent service system, and apply for debit cards through face recognition technology and instructions. It takes only a few minutes to get it done. The intelligent customer service system mainly obtains customer information through computers, mobile APPs, outlets and social networking sites, and conducts question-and-answer human-computer collaboration dialogues. The customer can use the online intelligent customer service to interact, consult or handle relevant business, etc. If necessary, the human service function can be transferred. The customer does not need to go to the on-site counter to conduct service consultation of handle related business, etc. It can improve operational efficiency, increase customer satisfaction with financial services, and help financial institutions ease operational pressure and control costs.

\section{B. Smart Credit Scoring}

In the past, most credit scoring models were based on traditional credit score sheets, historical credit information or customer's lengthy transaction data, using data statistics systems and regression analysis models to generate customer credit scores. However, if the customer does not have historical credits information, we will not get the credit score. Now the smart credit score can be based on the customer's consumption habits and social network data, through screening, sorting, analysis of effective data, evaluation of consumer behavior and willingness to pay and other qualitative factors, to generate customer credit scores.

\section{Intelligent Investment Consultant (Robo-advisor)}

The traditional investment advisory service characterizes face-to-face communication. The investment consultant understands the customer's basic situation and some specific question-and-answer models, such as the customer's financial status, investment demand, risk tolerance, and income level. The target information summarizes the customer's needs, and then the consultant provides investment consulting services for customers. Customers can also learn about the relevant financial knowledge and look for investment consultants according to their own needs. Some related expenses, such as service fees, management fees, and commissions, will also be incurred during this process.

Robo-advisor is built upon the investor's expected return rate, risk preference, investment period and other factors, based on algorithmic online investment consultants and asset management services, using artificial intelligence related technology to tailor a professional investment strategy for customers[2]. That is, when you choose the investment period and risk reward, the Robo-advisor will generate a portfolio, which is chosen by the customer. At the same time, the customer can also obtain the information of the wealth management product through Robo-advisor, and collect consulting information to obtain the solution. The cost of the Robo-advisor service is much less than that of traditional investment consultants. According to the report of iResearch's "AI changes finance: the landing of artificial intelligence, leading financial intelligence", the scale of China's Roboadvisor market has increased from 39.75 billion in 2017 to 2018 exceeding 100 Billions, indicating that China has increased its support for Robo-advisor, and the Robo-advisor technology will be more mature[1]. It is estimated that in 2020, China's Robo-advisor market will exceed 180 billion yuan, and the growth rate will reach $74.5 \%$. It can be predicted that the investment advisory model of the financial industry in the future will be more intelligent.

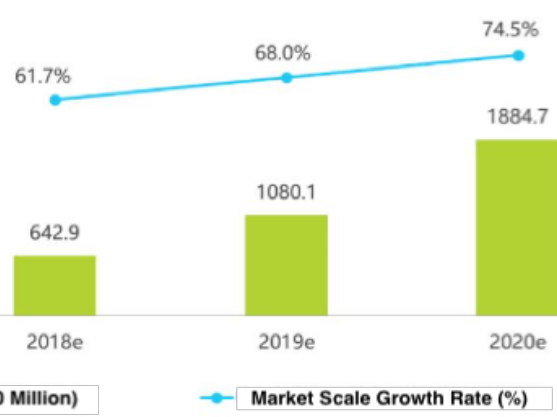

Fig. 2. The scale of China's smart investment market in 2017-2020

Source: iResearch "AI changes finance: the landing scene of artificial intelligence, leading financial intelligence"[1]

\section{Intelligent supervision services and improved data quality}

With the rapid development of the financial industry, regulators are constantly proposing new reporting requirements for financial institutions. The financial industry needs a huge amount of data to complete the report, but these data may have major errors and cannot guarantee the reliability. Governments need a lot of manpower to check whether the data is accurate. While using artificial intelligence technology to detect the data, it will automatically detect the errors and make marks, which can improve the accuracy and the quality of the data, reduce cost, and maintain data regulation. The application of artificial intelligence in financial markets to monitor transaction data and investors' trading behaviors, can improve the transparency of financial markets, prevent manipulation and abuse of market behavior, and make financial markets more fair, just and open. 


\section{E. Intelligent Quantitative Trading}

Artificial intelligence can also be applied in financial transactions in the financial industry. It is called intelligent quantitative trading, which is to use some financial data for modeling and regression analysis, developing trading strategies to providing references or solutions to complex investment issues. At present, companies such as Quantitative Technology and Jinna Technology use the technology of intelligent quantitative trading to conduct transactions.

\section{THE IMPACT OF ARTIFICIAL INTELLIGENCE ON THE FINANCIAL INDUSTRY}

With the accelerated development of artificial intelligence technology in the financial field and the wide range of applications, the financial industry has undergone new changes. The penetration of artificial intelligence technology in the financial field has brought convenience and impact to the financial industry. The impact of artificial intelligence on the financial industry will be explained from three perspectives: financial markets, financial institutions, and endusers.

\section{A. The impact of artificial intelligence on financial markets}

\section{1) Positive impacts are as follows}

The operation of financial market requires a large amount of data, such as transaction data in financial markets, financial accounts of the company, and basic consumption data of investors, etc. Manual processing may result in erroneous data entry, and it takes a lot of time. Artificial intelligence can collect and analyze more data, reduce the asymmetry of financial market transaction information, and promote traders in financial markets to understand the relationship between the formation of transaction prices and various factors. When traders obtain the trading information, they will know how to invest, and the blind followers of financial markets will diminish. This will also help improve the stability and operational efficiency of financial markets, increase the trading volume of financial markets, reduce transaction costs and promote finance market liquidity.

Artificial intelligence can find the most valuable range from the historical transaction data and historical trend of the financial market, so that the financial market is more regular, which helps the investors in the financial market to better predict the optimal transaction price in trading hours.

The application of the artificial intelligence in the financial industry has saved manpower and reduced costs in the financial market, and some non-technical jobs have been replaced by artificial intelligence to improve accuracy and efficiency[3].

\section{2) Negative impacts are as follows}

The penetration of artificial intelligence in the financial market may also bring potential risks. If the financial market traders, including both individual investors and institutional investors, use artificial intelligence as a technology for illegal operations, for themselves seeking private profits, this will affect the stability of the financial market.

The second is that insiders or senior suspects use the predictable model of artificial intelligence to manipulate the transaction price, which will disrupt the trading order of the financial market.

Third, although artificial intelligence will increase the trading volume and efficiency of financial markets, when market transactions are too frequent and in large-scale, which will increase the volatility of trading prices, and will also affect the stability of financial markets[4].

The fourth, artificial intelligence in the financial market may have regulatory loopholes. If the regulator does not propose a sound regulatory model and policy for the application of artificial intelligence in the financial industry and take risk prevention measures, it will bring huge fluctuations to the financial market.

\section{B. The impact of artificial intelligence on financial institutions}

\section{1) Positive impacts are as follows}

The application of the artificial intelligence in the financial industry, such as the intelligent customer service, intelligent risk control, intelligent investment consultant, and intelligent marketing, as mentioned above, changed the operation mode of the entire financial industry. Some posts are replaced or reduced, such as human customer service, as well as the front desk, lobby manager, and tellers. When financial institutions use artificial intelligence to handle various operations, it will reduce human errors, improve accuracy and efficiency, in processing daily business, collecting and analyzing customer basic information, consumer trading behavior, and tailoring for customers. Artificial intelligence can also analyze social network information to explore potential customers and improve the performance of financial institutions.

\section{2) Negative impacts are as follows}

First, when the artificial intelligence tool has a bug, it will bring losses to the users, such as financial institutions and investors. If the loss is to be borne by the user, the responsible party cannot be defined. When the supplier provides this service to the financial institution, it should clearly explain the problem. The contract is the contract. Both the financial institution and the investor should also sign an agreement to avoid these follow-up problems.

The second is that, when investors use artificial intelligence in financial institutions, but do not fully understand the operation and follow the investment strategy formulated by artificial intelligence to invest, but underestimate the investment risk that may bring losses to investors.

The third is that, artificial intelligence development process is inconsistent with the internal policies and procedures of financial institutions, which may lead to erroneous judgment.

\section{Potential impact on consumers and investors}

1) Positive impacts are as follows

First, the application of artificial intelligence in the financial industry reduces the labor cost. The use of artificial intelligence simplifies the credit approving process. Consumers and investors only need to provide transaction formalities to apply for credit business. 
Second, consumers and investors can gain access to a wider range of financial services. Robo-advisor can be achieved according to the investment period, the expected investment rate and risk tolerance of consumers, online data modeling and analysis, to provide consumers and investors with customized investment services, and investors can get online consultation of Robo-advisor service[5].

Third, artificial intelligence can clearly capture the basic information of consumers and investors through data analysis, and provide personalized services according to their consumption and investment preferences.

\section{2) Negative effects}

The first is that consumer or investor may experience incorrect operation due to unfamiliar use of the artificial intelligence, which may result in losses. Secondly, artificial intelligence uses big data to analyze the characteristics of consumers and investors, which is equivalent to the fact that consumers' information in investors is transparent and open, which may lead to privacy security issuer.

\section{Countermeasures in The FACE OF ARTIFICIAL INTELLIGENCE IN THE FINANCIAL INDUSTRY}

The development and application of artificial intelligence in the financial industry has changed the model of the financial industry. From the traditional to the intelligent, the service is more personalized and professional, and the liquidity of the financial industry is promoted. At the same time, the popularization of artificial intelligence also brings some negative effects. Therefore, the financial industry needs to make countermeasures to prevent potential risks brought about by artificial intelligence.

Firstly, the users, consumers and investors should fully understand the rules of artificial intelligence before using it, and reduce erroneous operations to avoid unnecessary losses. Consumers and investors must abide by laws and regulations, and should not use artificial intelligence to conduct illegal operations. Consumers and investors should also fully understand how to operate with intelligent service systems. Artificial intelligence had brought conveniences to users, but new technologies always have double blades. The consumers and investors should bear that in mind.

Secondly, financial institutions should independently manage the use of artificial intelligence and establish a technical monitoring department. Financial institutions should also establish a risk prevention and control system, improve risk management capabilities, set up a supervision team, and regularly test artificial intelligence system. The standards of artificial intelligence should be established to standardize the use of artificial intelligence, and improve the production process of artificial intelligence. It must match the internal procedures and policies of financial institutions, thus to provide personalized financial services for financial institutions. Financial institutions should popularize the knowledge of financial intelligence systems for consumers and investors.

Third, financial regulators should strengthen supervision of financial institutions that use artificial intelligence technology, and urge financial institutions to fully understand the rules. The government should also increase research on artificial intelligence, and gradually establish and improve laws and regulations for the use of artificial intelligence. The use of intelligent service systems requires the collection of a large amount of personal data. Relevant service organizations and official websites must control the authenticity of data, build a data protection security system, and prevent criminals from invading databases. The government should make more and strict laws on the collection of privacy data. European Union had set a very good example on the enactment of GDPR, which should be carefully studied by other countries. The popularity of artificial intelligence today has also raised concerns in human community like whether machines will completely replace human jobs, whether artificial intelligence is safe and controllable, etc. Only by strengthening the research of artificial intelligence ethics and dealing with the new relationship between machines and human beings, artificial intelligence can better serve us. The role of the government is indispensable. Laws should cover such aspects of human concerns.

\section{CONCLUSION}

In the era of artificial intelligence, the financial industry is actively transforming the service model and taking the lead in embracing intelligence. Artificial intelligence will be more widely used in the financial industry. At present, the application of artificial intelligence in the financial industry is mainly in intelligent customer service, intelligent marketing, intelligent investment, intelligent risk control, and intelligent quantitative trading. The application of artificial intelligence in the financial industry will also have different impacts on financial markets, financial institutions, investors and consumers. Some countermeasures analysis is proposed for the negative impact of the use of artificial intelligence in the financial industry.

In the future, the popularization of artificial intelligence will make the services of the financial industry more simple, personalized and professional. The acceptance of artificial intelligence by financial institutions will be more promising. It is hoped that the financial industry will be able to control the unfavorable factors while enjoying the intelligent services, improve the quality of the entire financial industry, operational efficiency, and move toward better development.

\section{REFERENCES}

[1] iResearch, AI changes finance: artificial intelligence landing scene, leading financial intelligence, Retrieved February 6, 2019 (In Chinese)

[2] M. Fein, Robo-Advisors: A closer look. Prepared for Federated Investors, Inc, 2015.

[3] R.Weber, Back to the (Technology) Future. Journal of Financial Service Professionals 70, 2016, pp. 42-45.

[4] Zhuoyue Yang, AI application in the Financial Area and Security Analysis. Finance Economy, 2017, (2):147-148. (In Chinese)

[5] Y. Feng, \& D. Sun, Opportunities and challenges of robo-advisor industry. Financial Technology Time. 6(1), 2017. pp.17-24(In Chinese) 